\title{
Analeptics and the Resuscitation of Asphyxiated Monkeys*
}

\author{
S. S. DANIEL, † PH.D. ; G. S. DAWES, $\ddagger$ D.M. ; L. S. JAMES,§ M.D. ; B. B. ROSS, $\|$ PH.D.
}

Brit. med. F., 1966, 2, 562-563

The use of analeptics, such as lobeline and nikethamide, in the resuscitation of newborn human infants who fail to breathe after birth has been abandoned in some hospitals. Their use has been abandoned for theoretical reasons, that these drugs are believed to act mainly by stimulating the systemic arterial chemoreceptors, which must already be strongly excited by asphyxia; for practical reasons, that experiments on adult animals deprived of oxygen suggested that these drugs were ineffective, or less effective than positive-pressure ventilationfor example, Eastman and Kreiselman (1941) -and as a result of extensive clinical experience (Resuscitation of Newborn Infants, 1956). Nevertheless, their use continues to be advocated in some textbooks, and these drugs are still available and used occasionally in the delivery rooms of many hospitals. From time to time we have received personal anecdotal reports from house staff in Great Britain and the U.S.A. who are convinced that, in particular instances, injections of these drugs have caused an asphyxiated infant to gasp.

We have thought it desirable to examine the matter again in view of these reports, and because such drugs may also have a reflex effect on breathing in newborn animals by exciting other sensory receptors (Dawes and Mott, 1959) or by central action. The design of the experiments was conditioned by the following considerations.

In adult, newborn, and foetal monkeys asphyxia causes the same pattern of change in the circulation and breathing. There is an initial period of hyperpnoea. This ceases abruptly and is succeeded by an apnoeic interval which has been designated "primary apnoea." The cessation of respiratory movements is accompanied by convulsive activity and an abrupt fall in heart rate. Primary apnoea may last for one to three minutes, at the end of which deep gasping movements start and succeed each other at fairly regular intervals. The gasps gradually become weaker, and the last gasp (in the absence of subsequent effective resuscitation) can be recognized with certainty. The period after the last gasp is defined as "secondary apnoea." The time to last gasp in foetal monkeys is about eight minutes, and in adult monkeys is slightly less. With these facts in mind it was decided to test the effects of analeptics during both primary and secondary apnoea.

\section{Methods}

The monkeys used in these experiments were separated into three groups according to age-adult, newborn, and foetal. Both adult and newborn monkeys were asphyxiated for periods of up to six minutes by occluding the airway. These two groups were subjected to repeated episodes of asphyxia up to a total of seven times, with a 45-minute recovery period between each episode. The foetal monkeys were asphyxiated once only. In all groups resuscitation was accomplished, when necessary, by positive-pressure ventilation with oxygen. The details of procedure used with each group follow.

- From the Laboratory of Perinatal Physiology, National Institute of Neurological Diseases and Blindness, San Juan, Puerto Rico. † Columbia Presbyterian Medical Center, New York, U.S.A

Nuffield Institute for Medical Research, Oxford, England.

Columbia Presbyterian Medical Center, New York, U.S.A. ; Investigator, New York City Health Research Council, 1-148.

Department of Physiology, University of Oregon Medical School, Portland, Oregon, U.S.A.
Adult rhesus monkeys weighing $4.6-7.8 \mathrm{~kg}$. were lightly anaesthetized with sodium pentobarbitone (Abbott Laboratories, $20-25 \mathrm{mg} . / \mathrm{kg}$.) intravenously at a room temperature of $24^{\circ} \mathrm{C}$; they were not allowed to recover consciousness before asphyxiation. The trachea was cannulated and femoral arterial and intratracheal pressures were recorded with strain-gauge manometers, together with the electrocardiogram. A branch of the jugular vein was catheterized for intravenous injections.

Newborn rhesus monkeys 3 days old, weighing 415-453 g., were lightly anaesthetized with $15-20 \mathrm{mg}$. of sodium pentobarbitone per $\mathrm{kg}$. intravenously at a room temperature of $30^{\circ} \mathrm{C}$. The femoral arterial pressure and electrocardiogram were recorded. A femoral vein was catheterized for intravenous injections. An endotracheal tube, which had a flared portion to ensure a gas-tight fit at the larynx, was introduced.

Foetal rhesus monkeys of 131-137 days' gestational age (term is about 168 days) and $308-437 \mathrm{~g}$. weight were delivered under local anaesthesia. The foetus was asphyxiated by slipping a rubber bag containing a small quantity of saline over the head and tying the umbilical cord. The infant was at once placed on a table at an environmental temperature of $30^{\circ} \mathrm{C}$. Needle electrodes for recording the electrocardiogram were inserted subcutaneously. Blood-pressure was recorded by a strain-gauge manometer from a catheter inserted into an umbilical artery. A catheter was introduced into the umbilical vein for injection or infusion of drugs from a motor-driven syringe. After a predetermined period of asphyxia the infant was resuscitated.

In adult, newborn, and foetal monkeys the respiratory efforts during asphyxia were timed with a stopwatch and the recorded time was checked by inspection of the respiratory artifacts on the electrocardiogram and arterial pressure records, and, in the adult, on the tracheal pressure records.

Arterial blood samples (approximately $0.8 \mathrm{ml}$.) were withdrawn at intervals. The $\mathrm{pH}$ was measured by means of a glass electrode with a reproducibility of $\pm 0.002 \mathrm{pH}$ units at $38^{\circ} \mathrm{C}$. The values obtained were corrected for the difference between this and deep body temperature (Adamsons et al., 1964b). The $\mathrm{PCO}_{2}$ and total $\mathrm{CO}_{2}$ content were calculated by the method of Siggaard Andersen et al. (1960). Lactate was determined by a micro-modification of the method of Barker and Summerson (1941).

\section{Results}

In five adult monkeys asphyxiation caused a fall in mean arterial $p H$ from $7.36 \pm 0.01$ to $7.11 \pm 0.01$ in five minutes, while the $\mathrm{PCO}_{2}$ rose from $38.1 \pm 1.7$ to $78.7 \pm 4.8 \mathrm{~mm}$. $\mathrm{Hg}$, and the blood lactate concentration rose from $2.1 \pm 0.33$ to 6.6 $\mathrm{mM} / 1$. (range 5.4-7.3, three observations). Qualitatively similar changes were observed in newborn monkeys asphyxiated in the same way, and in foetal monkeys asphyxiated on delivery-for example, Adamsons et al. (1963, 1964a). The arterial pH, $\mathrm{PCO}_{2}$, blood-pressure, and heart rate of adult and newborn monkeys returned to control values after 45 minutes' recovery before the animals were asphyxiated again.

In the adult monkeys occlusion of the tracheal cannula caused hyperpnoea lasting for a mean of $2.28 \pm 0.12$ minutes (S.E.), followed by primary apnoea (as previously defined) for $1.57 \pm$ 0.21 minutes. Gasping then ensued. (An intravenous injec- 
tion of lobeline (1-2 mg./ $\mathrm{kg}$.) into unasphyxiated adult monkeys caused hyperpnoea after a latent period of about five seconds, lasting about 45 seconds.) Injection of the same dose of lobeline into asphyxiated adult monkeys $0.3-0.5$ minutes after the onset of primary apnoea reduced its duration significantly to $0.87 \pm$ 0.04 minute $(P<0.05)$. Hence lobeline can act as a respiratory stimulant during primary apnoea in the asphyxiated adult.

Intravenous injections of lobeline $(1-2 \mathrm{mg} . / \mathrm{kg}$.) or nikethamide $(0.6 \mathrm{ml} ., 25 \% \mathrm{w} / \mathrm{v})$ caused intense hyperpnoea in unasphyxiated newborn monkeys, both mature and immature, with convulsions after nikethamide. The doses used are those commonly recommended on a weight-for-weight basis. Injections of lobeline also reduced the duration of primary apnoea in three asphyxiated newborn monkeys, though the numbers of observations were insufficient for statistical analysis.

Injection of lobeline and nikethamide into four asphyxiated foetal monkeys after the last gasp-that is, during secondary apnoea-did not elicit any gasp, and both caused a fall in arterial pressure (Fig. 1B). The monkeys were subsequently resuscitated successfully by positive-pressure ventilation. The results with lobeline and nikethamide contrast unfavourably with the effect of infusion of alkali and glucose solution (Tris $0.5 \mathrm{M}$ with $3.5 \%$ glucose, $\mathrm{pH}$ adjusted to 8.85 ). Intravenous infusions of the latter at $3.8 \mathrm{ml} . / \mathrm{kg}$. minute into five foetal monkeys asphyxiated for one minute or more beyond the last gasp caused a rapid rise in blood-pressure and heart-rate (Fig. $1 \mathrm{~A})$, and all the monkeys began to gasp again.

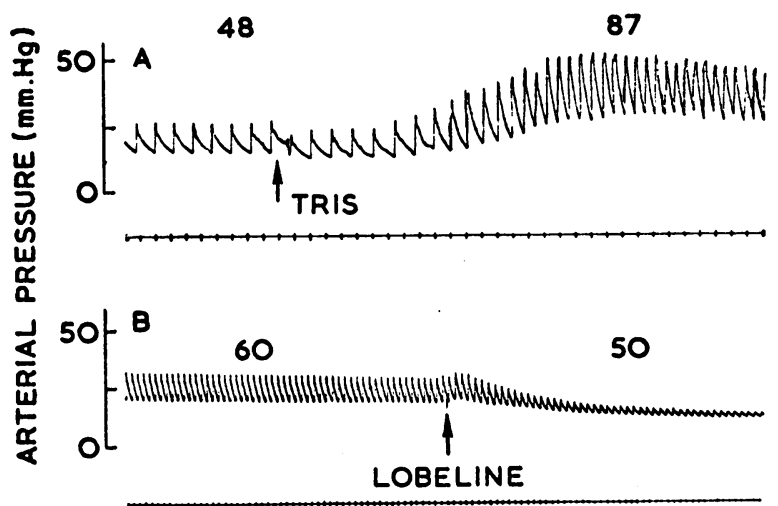

FIG. 1-Observations on two immature foetal monkeys delivered by caesarean section and asphyxiated by tying the umbilical cord ; the head was covered by a bag containing a small quantity of saline. Drugs were injected during secondary apnoea, one minute after the last gasp. Injections of alkali (Tris) in A caused a rapid rise in heart rate (indicated by the numerals above the arterial pressure record in beats/min.) and after 25 seconds the monkey began to gasp again (the consequent disturbances can just be detected in the pressure record). Injection of lobeline $(2 \mathrm{mg}$. $/ \mathrm{kg}$.) in $B$ caused the arterial pressure to fall more rapidly ; heart rate continued to decrease and there were no further respiratory efforts. Time scales in seconds.

\section{Discussion}

Lobeline and nikethamide were chosen for this investigation because they are the two analeptics most widely used and whose modes of action have been thoroughly studied, if not always in the circumstances under discussion. Eastman and Kreiselman (1941), for instance, used adult dogs and reported that lobeline did not excite respiratory efforts during asphyxial apnoea. The distinction between primary and secondary apnoea had not been made when they wrote, and it was for this reason that we thought their experiments worth repeating upon adult monkeys.

The results show that in asphyxiated aduit and newborn monkeys injection of lobeline during primary apnoea leads to the animal taking a gasp earlier than it otherwise would have done. No attempt has been made to analyse the mechanisms involved. However, this observation accords with the occasional reports that analeptics have induced gasping in human infants asphyxiated at birth. In the early stage of asphyxia apnoeic newborn animals of many species react to a variety of stimuli. In the later stages of asphyxia in secondary apnoea-that is, after the last gasp-injection of lobeline or nikethamide elicited no respiratory effort and there was a more rapid fall of arterial pressure. This may have been due to the drug, injected into a failing circulation, reaching the coronary arteries in an unusually high concentration. This result is in striking contrast to the effect observed on injection of alkali and glucose (Fig. 1), which shows that the circulation is still capable of recovery and that respiratory efforts may yet be restored even in the presence of continuing asphyxia.

From the practical point of view the use of these analeptics in asphyxia neonatorum does not seem justified. If the infant is in secondary apnoea they may be positively dangerous, because of the effect on the circulation, and in primary apnoea they are unlikely to be as certain in restoring oxygen consumption and normal breathing as positive-pressure ventilation. Injection of alkali and glucose has proved a useful adjunct to resuscitation in asphyxiated foetal rhesus monkeys, can prevent or reduce brain damage, and has been recommended for cautious clinical trial in association with positive-pressure ventilation (Dawes et al., 1964 ; Adamsons et al., 1964a, 1964b). It is not suggested that alkali-and-glucose injection should be given by itself.

Finally, these experiments illustrate vividly the need to test new drugs, alleged to be useful in resuscitation at birth, in animals, under conditions which provide a reasonable model of the clinical situation, before they are used in man. They should be tested for their efficacy in both primary and secondary apnoea, and the results compared with those obtained from the use of the standard method of resuscitation-namely, intermittent positive-pressure ventilation.

\section{Summary}

Injection of lobeline into asphyxiated adult and newborn rhesus monkeys during "primary apnoea" caused them to gasp earlier than they otherwise would have done.

Injection of lobeline or nikethamide into foetal monkeys in "secondary apnoea"-that is, asphyxiated beyond their last gasp-did not elicit any further gasp and caused the bloodpressure to fall more rapidly.

Infusion of an alkali-and-glucose solution into foetal monkeys after the last gasp caused a rise in heart rate and bloodpressure, and gasping started again.

The results explain why the use of analeptics in asphyxia neonatorum is still sometimes reported on favourably, but show that there are other more reliable and less dangerous methods of resuscitation.

This work was supported by grants from the United Cerebral Palsy Educational and Research Foundation and the United States Public Health Service, GM 09069. We also wish to thank the National Institute of Neurological Diseases and Blindness for making available to us the facilities for this investigation. We are much indebted to the staff of the Laboratory of Perinatal Physiology in San Juan, Puerto Rico, for their expert help and hospitality.

\section{REFERENCES}

Adamsons, K., Behrman, R., Dawes, G. S., Dawkins, M. J. R., James, L. S., and Ross, B. B. (1963). '. Physiol. (Lond.), 169, 679 - James, L. S., and Koford, C. (1964a). f. Pediat., 65, 807.

Daniel, S. S., Gandy, G., and James, L. S. (1964b). f. appl. Physiol., 19, 897.

Barker, S. B., and Summerson, W. H. (1941). F. biol. Chem., 138, 535 Dawes, G. S., and Mott, J. C. (1959). F. Physiol. (Lond.), $145,85$.

- Hibbard, E., and Windle, W. F. (1964). F. Pediat., 65,801., Eastman, N. J., and Kreiselman, J. (1941). Amer. F. Obstet. Gynec., 41,

Resuscitation of Newborn Infants (1956). Obstet. and Gynec, 8,336 Siggard Andersen, O., Engel, K., Jørgenson, K.; and Astrup, P $(1960)$.
Scand. F. clin. Lab. Invest., 12, 172. 